\title{
DEUS: CONCEITO NÃO-DISTRIBUTIVO DE SEGUNDA ORDEM?**
}

Edgar Marques

UERJ/CNPq

\begin{abstract}
In this paper I argue against Guido Imaguire's attempt of solving the christian mistery of the trinity by considering "God" a non-distributive second order concept.

Keywords: God, trinity, Imaguire.

Resumo: Discuto e critico neste artigo a tentativa de Guido Imaguire de resolver o mistério cristão da trindade ao considerar "Deus" como um conceito não-distributivo de segunda ordem.
\end{abstract}

Palavras-chave: Deus, trindade, Imaguire.

Guido Imaguire propõe, em um interessante artigo $^{1}$, uma solução ousada e original para o problema clássico, para o pensamento cristão, da compatibilização entre as afirmações de que há um só Deus e de que a tríade composta das pessoas Pai, Filho e Espírito Santo é Deus. A dificuldade de compreensão desse dogma reside na afirmação aparentemente paradoxal de que algo seja ao mesmo tempo uno e trino. Imaguire crê poder dissolver esse - então aparente - paradoxo por meio de uma reinterpretação do conceito de Deus à luz da teoria dos tipos lógicos desenvolvida por Bertrand Russell. No que se segue tentarei, na primeira seção, fazer uma exposição extremamente sucinta da solução proposta por Imaguire, apresentando em seguida, na

\footnotetext{
* Agradeço a Ulysses Pinheiro e Marco Ruffino, que leram uma versão anterior deste artigo e apresentaram valiosas críticas e sugestões.

1 Imaguire, Guido, "A teoria dos tipos lógicos e a trindade", in: Oliveira, M. e Almeida, C. (org.), O Deus dos filósofos modernos, Vozes, Petrópolis, 2002, 43-53.
} 
segunda seção, alguns argumentos contrários à aceitação de sua interpretação. O que tentarei mostrar no presente artigo é basicamente que "Deus" não pode de maneira nenhuma ser tomado como um conceito de segunda ordem, devendo, ao contrário, ser interpretado como um conceito de primeira ordem.

\section{I}

$\mathrm{Na}$ tentativa de análise semântica do termo "Deus" a primeira questão que se coloca diz respeito a se o devemos tomar por um nome próprio ou por uma descrição abreviada. Isto é, o problema inicial é se esse termo deve ser considerado nome de um objeto ou nome de um conceito. Imaguire argumenta $^{2}$, a meu ver com plena razão, que "Deus" tem de consistir em uma palavra conceitual - utilizo-me aqui de uma tradução literal da expressão fregeana Begriffswort -, pois caso contrário (a) o discurso politeísta seria aprioristicamente contrasensual, uma vez que não faria sentido falar de vários deuses, já que "Deus" seria o nome de um indivíduo e não o conceito determinador de um tipo de ente, e (b) não se poderia atribuir significamente existência a Deus, já que, sendo uma propriedade de segunda ordem, a existência é afirmada de conceitos e não de objetos ${ }^{3}$. Tendo em vista, portanto, que a caracterização do termo "Deus" como um nome próprio acarretaria a negação de significatividade tanto ao discurso politeísta quanto às proposições nas quais afirmamos ou negamos que Deus exista, parece ser mais sensato e apropriado que o tomemos como uma palavra conceitual e não como um nome próprio.

Tendo estabelecido que "Deus" consiste em uma palavra conceitual, Imaguire passa a investigar a natureza desse conceito levando em conta o desafio de tornar intelígível a afirmação cristã de que Deus é, ao mesmo tempo, uno e trino.

O cerne da dificuldade referente ao mistério da trindade emerge a partir da suposição inicial - fundamental para a formulação do problema de que Pai, Filho e Espírito Santo não são idênticos uns aos outros. Parece,

\footnotetext{
2 Na página 47 do texto supracitado.

3 Ironicamente, um dos argumentos que apresentarei na próxima seção contra a solução proposta por Imaguire lança mão precisamente dessa mesma idéia para mostrar que "Deus" não pode ser um predicado de segunda ordem.
} 
contudo, que a fé cristã afirma (1) que cada uma dessas pessoas distintas é Deus e (2) que Deus é uno. A conjunção dessas afirmações seria, obviamente, contraditório e paradoxal, pois, se um predicado é atribuído a três entes distintos, a unicidade não pode estar entre suas notas características, uma vez que, nesse caso, teríamos pelo menos três entes que instanciariam esse conceito, isto é, pelo menos três deuses.

O insight básico de Imaguire é o de que esse paradoxo pode ser evitado se, ao contrário da interpretação mais óbvia, não considerarmos "Deus" como um predicado que se atribui a objetos - isto é, um predicado de primeira ordem -, tomando-o, ao contrário, como um predicado que se atribui a predicados - isto é, um predicado de segunda ordem -. Ele introduz ainda uma nova especificação: tratar-se-ia de um predicado que se aplica a predicados de maneira não-distributiva. Isso significa que ao se aplicar a um determinado conjunto de predicados, esse predicado não pode ser atribuído em separado a cada um dos elementos que formam esse conjunto. Um predicado não-distributivo seria, por exemplo, o de "dupla". Podemos dizer que Batman e Robin quando tomados em conjunto constituem uma dupla, mas seria equivocado afirmar que Batman e Robin tomados isoladamente sejam cada um uma dupla.

A solução proposta por Imaguire consiste, assim, em considerar "Deus" um predicado de segunda ordem que se aplica ao predicado de primeira ordem "pessoa”. Esse predicado, por sua vez, aplica-se aos objetos logicamente simples Pai, Filho e Espirito Santo, que são referidos pelos nomes "Pai", "Filho" e "Espírito Santo". Esses objetos são, assim, pessoas e à reunião dessas pessoas aplica-se o predicado de segunda ordem "Deus"4. A aplicação desse predicado seria não-distributiva, de tal maneira que seria lícito tomar o conjunto formado por Pai, Filho e Espírito Santo como sendo Deus, mas não cada um deles em separado. Estariam afastadas, dessa forma, quaisquer possíveis conseqüências politeístas, pois "Pai", "Filho" e "Espírito Santo" não seriam Deus quando tomados isoladamente, mas unicamente

\footnotetext{
4 "Se considerarmos "deus" um predicado de segunda ordem, coloca-se automaticamente a questão, quais seriam então os predicados de primeira ordem na doutrina da trindade? Na teologia clássica foi proposto que Pai, Filho e Espírito Santo são três diferentes pessoas. (...) O predicado "pessoa" é o candidato ideal para o posto de predicado de primeira ordem. As expressões "Pai", "Filho" e "Espírito Santo" são tomadas aqui como nomes próprios, e correspondem aos objetos elementares no sentido da teoria dos tipos lógicos", Imaguire, G., op. cit., pág. 49.
} 
quando em conjunto. A unidade de Deus estaria, então, preservada, sendo, contudo, ainda plenamente significativa a afirmação de que Deus se apresenta como Pai, Filho e Espírito Santo.

Trata-se, sem dúvida, de uma solução extremamente original e ousada. Mas será que ela é aceitável? Na próxima seção apresento razões de duas ordens distintas que me fazem considerar equivocada a solução desenvolvida por Imaguire.

\section{II}

Podemos apresentar contra a solução proposta por Imaguire para o mistério da trindade argumentos de dois tipos distintos. Podemos, em primeiro lugar, mostrar que a aceitação de sua interpretação implica ou pressupõe teses acerca de Deus que contrariariam a concepção mesma de Deus da qual se parte para formular o problema. Na medida em que esse problema emerge precisamente a partir da tentativa de clarificação e racionalização de um conceito de Deus previamente dado, é claro que qualquer resposta que implique ou pressuponha teses acerca de Deus incompatíveis com esse conceito não pode ser vista como uma alternativa viável. Podemos, por outro lado, tentar mostrar que a solução proposta é em si mesma - e não em função de suas implicações - inaceitável simplesmente por ser conceitualmente incorreto considerar o conceito de Deus como um predicado de segunda ordem. No que se segue, tentarei apresentar contra Imaguire argumentos desses dois tipos, começando com os do primeiro.

Se aceitarmos a tese de que "Deus" deve ser interpretado como um conceito de segunda ordem, a primeira conseqüência imediata dessa aceitação consiste na impossibilidade de se afirmar, por meio de uma proposição significativa, que Deus existe, pois, não sendo o conceito de Deus atribuível a objetos - mas sim a outros conceitos -, não faz sentido dizer nem que Deus existe nem que não existe. Um conceito que não pode ser instanciado por objetos não pode dizer respeito a algo acerca do qual possamos produzir proposições significativas que envolvam a atribuição ou negação de existência, uma vez que a existência consiste ela mesma em uma propriedade de segunda ordem. A aceitação da solução de Imaguire implicaria, assim, a absurdidade da proposição "Deus existe", tornando a questão acerca da existência de Deus uma discussão desprovida de qualquer sentido. Essa conseqüência é, contudo, extremamente contra-intuitiva e contradiz a 
dogmática cristã da qual emerge o próprio problema da trindade, pois uma das teses fundadoras do cristianismo é exatamente a de que existe um único Deus. Sendo essa uma implicação direta da solução de Imaguire, parece claro que essa solução não pode ser aceita.

As dificuldade inerentes à solução de Imaguire estão vinculadas, contudo, não apenas à tese de que "Deus" é um predicado de segunda ordem, mas também à afirmação de que ele consiste em um predicado nãodistributivo que se aplica ao conjunto das pessoas (Pai, Filho e Espírito Santo), mas não a cada uma delas tomada isoladamente. O dogma da trindade, que dá ensejo ao problema que Imaguire tenta resolver, afirma, entretanto, que Deus está integralmente presente em cada uma das pessoas, sendo Deus, portanto, tanto a reunião das pessoas quanto cada uma das pessoas tomadas em separado. Ora, mas é exatamente essa característica idiossincrática do conceito cristão de Deus que não é capturada pela idéia da não-distributividade, pois um predicado não-distributivo é aquele que se aplica a um conjunto sem se aplicar aos seus membros. A atribuição de nãodistributividade ao atributo "Deus" não pode ser encarada, dessa maneira, como uma solução ao problema da trindade, mas sim como simples uma recusa do problema nos termos em que ele deve ser obrigatoriamente formulado.

A tese de que "Deus" é um atributo não-distributivo de segunda ordem é inaceitável, então, em primeiro lugar, por implicar a impossibilidade de se dizer significativamente que Deus existe ou não existe, transformando em nonsense uma parcela razoavelmente ampla de nossas proposições a respeito do divino. Ela é inaceitável, também, em segundo lugar, por pressupor que as pessoas (Pai, Filho e Espírito Santo) tomadas isoladamente não são Deus, o que contraria o dogma cristão que possibilita a formulação mesma do problema.

Além disso, independentemente dessas implicações e pressupostos, não me parece ser correto compreender o termo "Deus" como expressão lingüística de um conceito de segunda ordem. Conceitos de segunda ordem são predicados de conceitos de primeira ordem. Isso significa que a aplicação de um determinado conceito de segunda ordem ao universo formado pelos conceitos de primeira ordem possibilita diferenciar entre aqueles conceitos de primeira ordem ao quais o conceito de segunda ordem se aplica e aqueles aos quais ele não se aplica, isto é, permite diferenciar entre os conceitos de primeira ordem que possuem certas propriedades correspondentes às notas 
características do conceito de segunda ordem em questão e os conceitos de primeira ordem que não as possuem.

Essas propriedades, cuja posse possibilita que um conceito de primeira ordem caia sob um conceito de segunda ordem, são traços ou marcas presentes nos próprios conceitos de primeira ordem, e não nos objetos que, por sua vez, caem sob esses conceitos. Conceitos de segunda ordem são critérios de classificação de conceitos de primeira ordem, e não de objetos. $\mathrm{O}$ conceito de existência é, por exemplo, um conceito de segunda ordem, pois por meio dele podemos diferenciar os conceitos que caem sob ele - isto é, aqueles cuja extensão não é vazia - daqueles que não o fazem. Ele é um conceito de segunda ordem na medida em que nos fornece um critério para separar os conceitos em dois grupos em função do tipo de extensão que eles possuem.

Levando em conta essas considerações, simplesmente não consigo entender em que sentido o conceito de Deus poderia ser tomado como um conceito de segunda ordem, pois, ao menos à primeira vista, nada há nele que nos permita estabelecer quaisquer diferenças entre conceitos a partir de propriedades ou traços neles presentes. $\mathrm{Na}$ verdade, a interpretação natural do conceito de Deus é a de que ele diz respeito a um tipo de ente, e não a um tipo de conceito. E o texto de Imaguire não fornece nenhuma razão convincente, que nos force a abandonar essa "interpretação natural" do conceito.

Considero, assim, que apesar da original, ousada e, repito, interessante proposta de Imaguire, o mistério da trindade permanece o que sempre tem sido: um mistério.

Email: edgarm@terra.com.br

Recebido em: Abril/2010 Aprovado em: Junho/2010 